\title{
Hyperglycaemia confers resistance to chemotherapy on breast cancer cells: the role of fatty acid synthase
}

\author{
L Zeng ${ }^{*}, K M$ Biernacka*, J M P Holly, C Jarrett, A A Morrison, A Morgan, \\ Z E Winters, E J Foulstone, J P Shield and C M Perks
}

\author{
IGFs and Metabolic Endocrinology Group, Department of Clinical Sciences North Bristol, Learning \& Research Building, 2nd floor, \\ University of Bristol, Southmead Hospital, Bristol BS10 5NB, UK \\ (Correspondence should be addressed to C M Perks; Email: claire.m.perks@bristol.ac.uk) \\ *(L Zeng and K M Biernacka contributed equally to this work)
}

\begin{abstract}
The prognosis for women with breast cancer is adversely affected by the comorbidities of obesity and diabetes mellitus (DM), which are conditions associated with elevated levels of circulating fatty acids, hyperglycaemia and hyperinsulinaemia. We investigated the effects of exposure of nonmalignant and malignant human breast epithelial cells to elevated levels of fatty acids and glucose on their growth, survival and response to chemotherapeutic agents. We found that palmitate induced cell death in the non-malignant cells but not in the malignant cells, which was abrogated through the inhibition of ceramide production and by oleate but not by IGF1. Fatty acid synthase (FAS) is responsible for the de novo synthesis of fatty acids from sugars, and is over-expressed in many epithelial cancers. Abundance of FAS was higher in malignant cells than in non-malignant cells, and was up-regulated by IGF1 in both cell types. IGF-induced growth of non-malignant cells was unaffected by suppression of FAS expression, whereas that of malignant cells was blocked as was their resistance to palmitate-induced cell death. Palmitate did not affect cell proliferation, whereas oleate promoted the growth of non-malignant cells but had the opposite effect, that is, inhibition of IGF1-induced growth of malignant cells. However, when the phosphatidylinositol 3-kinase pathway was inhibited, oleate enhanced IGF1-induced growth in both cell types. Hyperglycaemia conferred resistance on malignant cells, but not on non-malignant cells, to chemotherapy-induced cell death. This resistance was overcome by inhibiting FAS or ceramide production. Understanding the mechanisms involved in the associations between obesity, DM and breast cancer may lead to more effective treatment regimens and new therapeutic targets.
\end{abstract}

Endocrine-Related Cancer (2010) 17 539-551

\section{Introduction}

Over the last few decades, there has been a rapid increase in the prevalence of obesity, and as a consequence, also of diabetes, which together now affect a significant proportion of the population. Breast cancer is the most common malignant neoplasm in women with a lifetime risk of 1 in 8 (Key et al. 2001), and increasingly, these women will also be affected by these metabolic disturbances; up to $16 \%$ of older breast cancer patients now suffer from diabetes (Coebergh et al. 1999, Yancik et al. 2001).

Obesity is associated with an increased risk of postmenopausal breast cancer, but with a reduced incidence of premenopausal disease (Calle \& Thun 2004), although a recent study demonstrated that obesity was associated with a $48 \%$ increase in mortality over a 8-10-year follow-up in premenopausal patients (Abrahamson et al. 2006). A number of cohort (Weiderpass et al. 1997, Wideroff et al. 1997, Michels et al. 2003, Coughlin et al. 2004, Silvera et al. 2005) and case-control studies (Talamini et al. 1997, Baron et al. 2001) have reported that patients with diabetes have an increased risk of breast cancer. A positive association between breast cancer mortality and diabetes was found in three of five studies, with the relative risk from the pooled data from the five studies 
being 1.24 (Larsson et al. 2007). Elevated blood glucose was associated with an increased risk of breast cancer in a population-based cohort of more than 140000 adults in Austria (Rapp et al. 2006). Cancer mortality is geographically correlated with the level of dietary sugar intake; countries with the greatest per capita sugar intake exhibit the highest rates of breast cancer mortality independent of other variables (Carroll 1977, Hems 1978). A number of epidemiological studies have shown a direct association between breast cancer risk and the consumption of sweet foods with high glycaemic index (Lubin et al. 1981, Landa et al. 1994, Potischman et al. 2002, Tavani et al. 2006). Studies have also provided evidence that high carbohydrate intake is associated with poorer survival after diagnosis for early breast cancer (Krone \& Ely 2005). Animal models of diabetes have also shown an increase in susceptibility to chemically induced mammary tumours (Shafie \& Grantham 1981). Together these studies indicate that obesity and diabetes are associated with poor prognosis in women with breast cancer.

Obesity results from a long-term energy imbalance, leading to an accumulation of lipid stores and an elevation of the circulating levels of fatty acids, predominantly oleate (unsaturated) and palmitate (saturated), the development of insulin resistance and hyperinsulinaemia, and eventually to hyperglycaemia and overt diabetes. Although considerable attention has been paid to the consequences of obesity and diabetes in relation to the actions of insulin (Manco et al. 2004), there has, however, been virtually no similar investigations on the effects on insulin-like growth factor 1 (IGF1), despite the considerable overlap between these hormones in terms of their receptors and intracellular signalling pathways (Foti et al. 2004). IGF1 has a very important role in the development and progression of many epithelial cancers, including that affecting the breast. The IGF1R plays a fundamental role in maintaining the transformed phenotype for many cancer cells (Baserga et al. 2003). In humans, recent prospective epidemiology has consistently shown strong associations between circulating IGF1 levels and the subsequent risk of developing prostate, colorectal and premenopausal breast cancers (Pollak et al. 2004). Individuals with circulating IGF1 levels within the upper end of the normal range are at a significantly increased risk of developing these cancers many years later.

Malignant cells utilise glucose as their main energy source (Garber 2004), and the associations of obesity, diabetes and breast cancer may be reflecting that increased energy supply promotes mammary carcinogenesis. However, glucose also acts as a substrate for fatty acid synthase (FAS). FAS is a key enzyme responsible for the de novo synthesis of fatty acids (Kuhajda et al. 1994), which is significantly up-regulated or activated in many cancer types including breast cancer, and has been associated with aggressive breast cancers (Kuhajda 2000). Knocking down FAS with siRNA enhances taxol-induced death of breast cancer cells (Menendez et al. 2005b), and inhibition of FAS also suppresses HER2/neu oncogene-induced malignant transformation (Menendez et al. 2004b).

In an attempt to identify the molecular mechanisms that may underlie the associations between obesity, diabetes and the increased risk and prognosis of breast cancer, we investigated the effects of the exposure to elevated levels of fatty acids and glucose on cell death and IGF-induced growth of non-malignant and malignant breast epithelial cells and their sensitivity to chemotherapeutic agents. In both these scenarios, we assessed the involvement of FAS.

\section{Materials and methods}

\section{Materials}

Recombinant, human IGF1 peptide was purchased from Gropep (Adelaide, South Australia, Australia). G-protein-coupled receptor (GPCR) inhibitor pertussis toxin (PT), phosphatidylinositol 3-kinase (PI3K) inhibitor LY294001 and MEK1 inhibitor UO126 were bought from Merck. FAS (S100059752) and control non-silencing siRNA were obtained from Qiagen. AntiFAS antibody was purchased from BD Biosciences (Cambridge, UK), anti-tubulin from Autogen Bioclear (Wiltshire, UK) and anti-GAPDH from Chemicon (Hampshire, UK). All other chemicals including an inhibitor of ceramide synthase (fumonisin B1), a chemical FAS inhibitor (C75), 5-fluorouracil, doxorubicin, D- and L-glucose, paclitaxel, palmitate and oleate were bought from Sigma-Aldrich. Tissue culture plastics were obtained from Greiner Labortechnik Ltd, Tyne and Wear, UK. The BCA protein assay reagent kit was purchased from Pierce (Rockford, IL, USA).

\section{Cell culture}

Human breast cancer cells, MCF-7 and T47D, and the non-malignant HMT-3522 S1 cells were purchased from ECACC (Porton Down, Wiltshire, UK), and grown in a humidified 5\% carbon dioxide atmosphere at $37^{\circ} \mathrm{C}$. MCF-7 and T47D cells were cultured in DMEM (BioWhittaker, Verviers, Belgium) supplemented with $10 \%$ foetal bovine serum (FBS, Gibco), 
penicillin (50 IU/ml; Britannia Pharmaceuticals, Redhill, UK), streptomycin $(50 \mu \mathrm{g} / \mathrm{ml}$; Celltech Pharmaceuticals, Slough, UK) and L-glutamine (2 mM; Sigma) - growth media (GM). The nonmalignant MCF-10A cell line was purchased from the American type culture collection (ATCC, Manassas, VA, USA). This is a spontaneously immortalised breast epithelial cell line that maintains a relatively normal phenotype as determined by 1) lack of tumourigenicity in nude mice, 2) exhibiting 3D growth in collagen, 3) control of growth by hormones and growth factors, 4) lack of anchorage-independent growth, and 5) formation of domes in confluent cultures (Soule et al. 1990). Unless otherwise stated, the MCF-10A and HMT-3522 S1 cells were maintained in 1:1 mixture of Ham's F12 medium and DMEM with $2.5 \mathrm{mM}$ L-glutamine (DMEM:F12, Gibco). For MCF-10A cells, the medium was supplemented with $5 \%$ horse serum (v/v HS, Gibco), penicillin and streptomycin (as described above), $20 \mathrm{ng} / \mathrm{ml}$ epidermal growth factor (EGF; Calbiochem, Nottingham, UK), $100 \mathrm{ng} / \mathrm{ml}$ cholera toxin (Sigma), $10 \mu \mathrm{g} / \mathrm{ml}$ insulin (Novo Nordisk, West Sussex, UK) and $0.5 \mu \mathrm{g} / \mathrm{ml}$ hydrocortisone (Sigma). HMT-3522 S1 cells were supplemented with $10 \% \mathrm{FBS}$, penicillin $(50 \mathrm{IU} / \mathrm{ml})$, streptomycin $(50 \mu \mathrm{g} / \mathrm{ml})$, insulin $(250 \mathrm{ng} / \mathrm{ml})$, transferrin $(10 \mu \mathrm{g} / \mathrm{ml})$, sodium selenite $(2.6 \mathrm{ng} / \mathrm{ml}$, Sigma), oestradiol $\left(10^{-10} \mathrm{M}\right.$, Sigma), hydrocortisone $\left(1.4 \times 10^{-6} \mathrm{M}\right)$, prolactin $(5 \mu \mathrm{g} / \mathrm{ml}$, Sigma) and EGF $(10 \mathrm{ng} / \mathrm{ml})$. Unless otherwise stated, experiments were performed in phenol red- and serum-free DMEM and Ham's Nutrient Mix F12 supplemented with penicillin and streptomycin (as described above), sodium bicarbonate $(0.12 \% \mathrm{w} / \mathrm{v}$; Sigma $)$, bovine serum albumin (BSA) $(0.2 \mathrm{mg} / \mathrm{ml}$; Sigma) and transferrin $(0.01 \mathrm{mg} / \mathrm{ml}$; Sigma) - serum-free media (SFM).

\section{Palmitate and oleate experiments}

Palmitate and oleate were dissolved in ethanol prior to mixing with $20 \%$ fatty acid-free BSA as described previously (Sabin et al. 2007b). The final concentration of BSA in serum-free media was adjusted to $0.1 \% \mathrm{w} / \mathrm{v}$.

MCF-10A, HMT-3522 S1 and MCF-7 cells were seeded in their respective GM in six-well plates (for assessing cell viability) or 24-well plates (for assessing cell proliferation). After $24 \mathrm{~h}$, the GM were replaced with SFM for a further $24 \mathrm{~h}$. For experiments examining the effects of palmitate on cell death, cells were then either dosed with palmitate alone $(0-400 \mu \mathrm{M})$, or pre-dosed with fumonisin B1 $(0.1 \mu \mathrm{M})$ for $30 \mathrm{~min}$ or co-dosed with IGF1 $(25 \mathrm{ng} / \mathrm{ml})$ or oleate $(400 \mu \mathrm{M})$, and left for $48 \mathrm{~h}$. Cell death was assessed using trypan blue cell counting. Any floating cells were collected and mixed with adherent cells following trypsinisation, and the resulting cell suspension was loaded onto a haemocytometer $(1: 1)$ with trypan blue dye, which is excluded by viable cells. Both viable and any dead cells were counted, from which, total cell number and the percentage of dead cells relative to control were calculated. For experiments examining the effects of oleate on proliferation, cells were dosed with either oleate alone (100 or $200 \mu \mathrm{M}$ respectively), IGF1 alone $(25 \mathrm{ng} / \mathrm{ml})$ or the combination of the two in the presence or absence of PT $(100 \mathrm{ng} / \mathrm{ml})$ or LY294002 $(5 \mu \mathrm{M})$, or they were subjected to a 30 -min preincubation with $\mathrm{U} 0126$ (1.5 or $1 \mu \mathrm{M}$ respectively), and left for $48 \mathrm{~h}$. Cell proliferation was assessed using tritiated thymidine incorporation as described previously (Burrows et al. 2006).

\section{Response to palmitate with FAS knocked down in MCF-7 cells}

MCF-7 cells were seeded in 24-well plates $(0.025$ $\times 10^{6}$ cells/well) in GM in the presence or absence of FAS (or non-silencing) siRNA (12 nM) before being switched to SFM for a further $24 \mathrm{~h}$ prior to dosing with palmitate $(400 \mu \mathrm{M})$ for $48 \mathrm{~h}$. Cell death was assessed as described previously, and FAS abundance was monitored using western immunoblotting as described below.

\section{Effects of blocking FAS on IGF-induced proliferation}

\section{FAS siRNA and $C 75$ experiments}

MCF-10A and MCF-7 cells were seeded in their respective $\mathrm{GM}$ in 24-well plates $(0.05$ and 0.025 $\times 10^{6}$ cells/well respectively) in the presence or absence of FAS (or non-silencing) siRNA (12 nM) before being switched to SFM for a further $24 \mathrm{~h}$ prior to dosing with IGF1 $(25 \mathrm{ng} / \mathrm{ml})$ for $48 \mathrm{~h}$, or after seeding in the GM for $24 \mathrm{~h}$, the cells were placed into SFM for a further $24 \mathrm{~h}$ prior to dosing with IGF1 $(25 \mathrm{ng} / \mathrm{ml})$ with or without $\mathrm{C} 75$ for $48 \mathrm{~h}$. Cell proliferation was assessed using tritiated thymidine incorporation, and FAS abundance was monitored using western immunoblotting of whole cell lysates as described below.

\section{Western immunoblotting for FAS}

Cells were seeded in their respective GM in six-well plates $\left(0.2\right.$ and $0.1 \times 10^{6}$ cells/well respectively). After $24 \mathrm{~h}$, the GM were removed and replaced with SFM. After a further $24 \mathrm{~h}$ in SFM, cells were dosed with or without IGF1 $(0-50 \mathrm{ng} / \mathrm{ml})$ for $48 \mathrm{~h}$. Cell lysis and 
western immunoblotting preparation were done as published previously (Burrows et al. 2006). Nonspecific binding sites on the nitrocellulose membranes were blocked overnight with $1 \% \mathrm{w} / \mathrm{v}$ milk in trisbuffered saline Tween-20 (TBST) for tubulin (1:1000), and with 5\%w/v TBST for FAS (1:1000) and GAPDH (1:10 000). Following the removal of excess unbound antibody, an anti-mouse antibody (1:5000 for FAS and tubulin, and 1:10000 for GAPDH) conjugated to peroxidase was added for $1 \mathrm{~h}$. Chemiluminescence was detected using the ChemiDoc-IT Imaging System (UVP, Bio-Rad), and analysed using Vision Works ls Analysis Software (UVP Inc., Upland, CA, USA).

\section{Hyperglycaemia experiments}

\section{Media}

All cells were cultured in either high $(25 \mathrm{mM})$ or normal $(5 \mathrm{mM})$ glucose-containing DMEM (Lonza, Berkshire, UK) supplemented with $10 \%$ FBS (Gibco), penicillin (50 IU/ml; Britannia Pharmaceuticals), streptomycin $(50 \mu \mathrm{g} / \mathrm{ml}$; Celltech Pharmaceuticals) and L-glutamine (2 mM; Sigma) GM. All cell line experiments were performed in the identical GM without serum - SFM. Initial experiments were also performed with media containing normal glucose $(5 \mathrm{mM})$ and supplemented with $20 \mathrm{mM}$ L-glucose in order to exclude confounding effects not mediated by enhanced glucose metabolism, such as osmotic effects.

\section{Dosing protocol}

Cells were seeded in six-well plates in normal glucosecontaining GM for $24 \mathrm{~h}$. They were then switched to either normal or high glucose-containing SFM for a further $24 \mathrm{~h}$ prior to dosing in the respective SFM with 5-fluorouracil $(0-40 \mu \mathrm{M})$, doxorubicin $(0-1 \mu \mathrm{M})$ or paclitaxel $(0-125 \mu \mathrm{M})$ for $24 \mathrm{~h}$. MCF-7 and T47D cells were also seeded in six-well plates at $0.1 \times 10^{6}$ as described above, and following $24 \mathrm{~h}$ in either normal or high glucose-containing SFM, they were dosed with paclitaxel $(50 \mu \mathrm{M})$ or 5-fluorouracil $(20 \mu \mathrm{M})$ respectively in the presence or absence of C75 $(7.5 \mu \mathrm{M})$ or were subjected to a 30-min pre-incubation with fumonisin B1 $(0.1 \mu \mathrm{M})$. Cell death was assessed as described previously.

\section{Statistical analysis}

The data were analysed using SPSS 12.0.1 for windows software using ANOVA followed by least significant difference post-hoc test. A statistically significant difference was considered to be present at $P<0.05$.

\section{Results}

Palmitate, but not oleate, differentially affects cell death of non-malignant MCF-10A and malignant MCF-7 breast epithelial cells

Palmitate induced a significant increase in cell death of both non-malignant cell lines, MCF-10A $(P<0.001$, Fig. 1A) and HMT-3522 S1 $(P<0.001$, Fig. 1B), whereas oleate had no effect on cell death. In contrast, the MCF-7 cells were resistant to the effects of both palmitate and oleate on apoptosis (Fig. 1C). One route of palmitate metabolism within the cell is as a substrate for the generation of ceramide, an important intracellular signalling intermediary. An inhibitor of ceramide production, fumonisin B1 (ceramide synthase inhibitor), abrogated the induction of MCF-10A cell death by palmitate (Fig. 1D), indicating that the cell death was at least partly due to ceramide generated from the palmitate. Palmitate-induced cell death was also inhibited in the presence of oleate (Fig. 1E), but interestingly not by IGF1 (Fig. 1F).

\section{FAS over-expression mediates the resistance to palmitate-induced cell death in malignant MCF-7 breast epithelial cells}

Palmitate is produced de novo within the cells from sugars by the action of FAS. We confirmed that the malignant cells markedly over-expressed FAS relative to the non-malignant cells (Fig. 2A) as reported previously (Kuhajda 2000). In the MCF-7 cells, exposure to palmitate was able to induce a significant increase in cell death $(P<0.001$; Fig. 2B) when FAS was knocked down using FAS siRNA, inferring that the resistance to palmitate may be acquired tolerance due to the high endogenous production of palmitate within the cell.

\section{IGF1 regulates abundance of FAS}

The abundance of FAS protein was dose dependently increased by IGF1 in both non-malignant MCF-10A and malignant MCF-7 cell lines (Fig. 3A). In order to determine the relevance of this novel regulation of FAS by IGF1, we knocked down FAS using siRNA, and also blocked its activity with a chemical FAS inhibitor, C75, and assessed how this affected the response to IGF1. The ability of IGF1 to increase the growth of non-malignant cells $(P<0.001)$ was unaffected when FAS was knocked down with siRNA (Fig. 3B(i)). The ability of IGF1 to increase the growth of this cell line $(P<0.001)$ was also unaffected in the presence of the chemical FAS inhibitor (C75; Fig. 3C). In the breast cancer cells, however, when FAS was knocked 

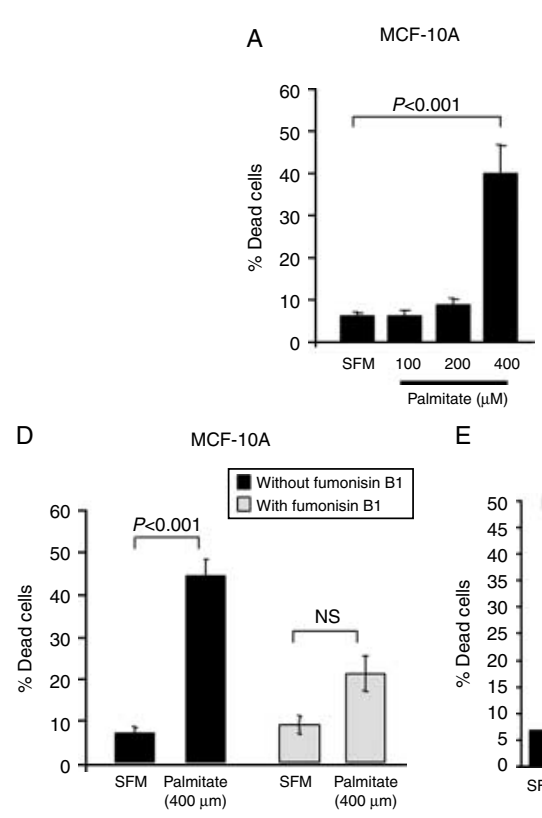

E MCF-10A
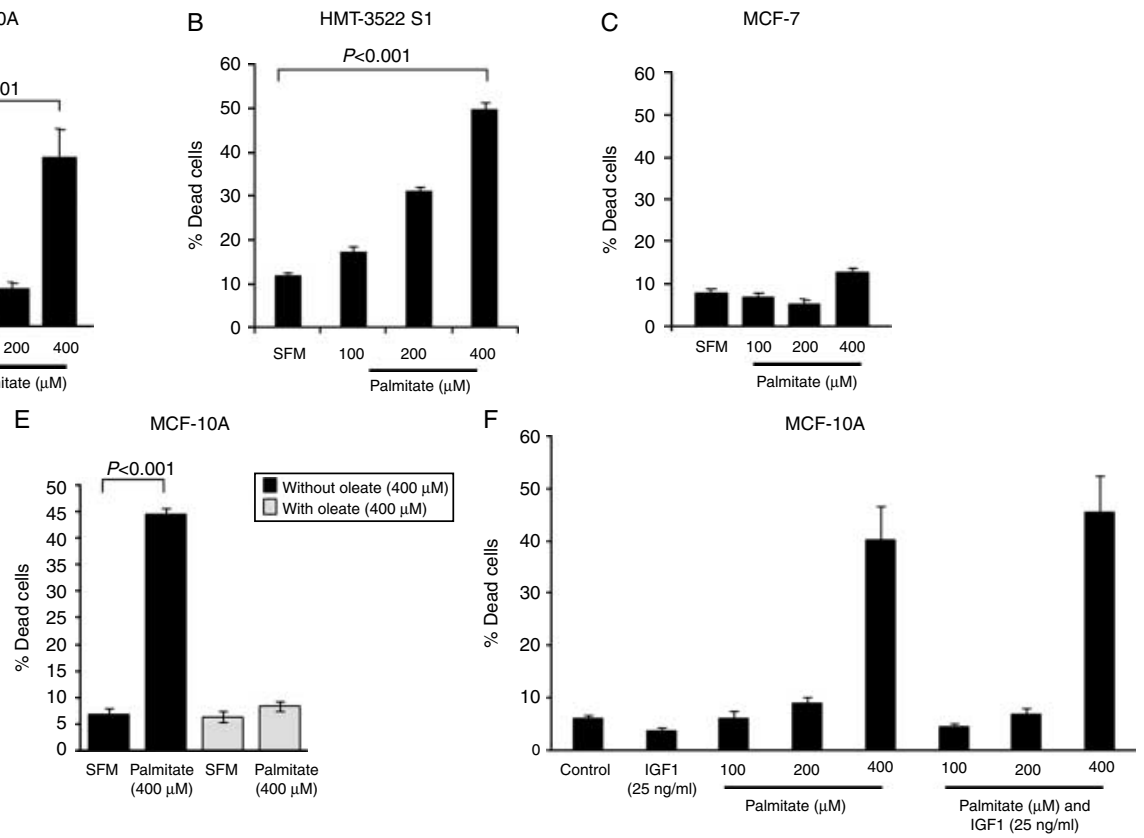

Figure 1 Palmitate, but not oleate, differentially affects cell death of non-malignant MCF-10A and HMT-3522 S1 and malignant MCF-7 breast epithelial cells. MCF-10A, HMT-3522 S1 ( $0.2 \times 10^{6}$ cells/well respectively) and MCF-7 (0.15 $\times 10^{6}$ cells/well) cells were seeded in six-well plates in GM followed by $24 \mathrm{~h}$ in SFM. Cells were then dosed \pm palmitate $(0-400 \mu \mathrm{M}$; A-C respectively) in the presence or absence of fumonisin B1 $(0.1 \mu \mathrm{M}$; D) or oleate $(400 \mu \mathrm{M} ; \mathrm{E})$ or IGF1 $(25 \mathrm{ng} / \mathrm{ml} ; \mathrm{F})$ for 48 h. Graphs represent changes in cell death, and show the mean \pm s.E.M. of three experiments, each repeated in triplicate.

down or inhibited, using siRNA (Fig. 3D(i)) or C75 (Fig. 3E), the ability of IGF1 to increase cell growth was completely blocked.

\section{Oleate, but not palmitate, modulates IGF-induced growth}

In order to assess the effects of fatty acids on the response to IGF1, we initially analysed the doseresponses to oleate and palmitate $(0-400 \mu \mathrm{M})$ in both malignant, MCF-7, and non-malignant, MCF-10A, breast epithelial cells, from which, we selected doses most effective in altering IGF-induced growth (data not shown). Whereas palmitate had no effect on IGF-induced growth in either cell line, oleate exerted effects on IGF-induced proliferation, which differed between non-malignant and malignant breast epithelial cells. In MCF-10A cells, both oleate and IGF1 alone were each able to significantly increase cell proliferation $(P<0.001$ for each), and together produced an additive increase in DNA synthesis $(P<0.001$; Fig. 4A-C). In contrast, in MCF-7 breast cancer cells, oleate alone had no effect on cell growth, but it significantly reduced $(P=0.001)$ the proliferative response to IGF1 (Fig. 4D-F).

It has been reported that GPCR may mediate the effects of oleate on breast cancer cells (Hardy et al. 2005); we, however, found that a GPCR inhibitor, PT, had no effect on the ability of oleate, at the physiological doses used, to modulate IGF responses in either MCF-10A or MCF-7 cells (Fig. 4A and D). In contrast, PT did inhibit the ability of a well-characterised agonist of GPCR, sphingosine-1-phosphate (S-1P), to induce cell proliferation in both non-malignant and malignant cells (data not shown).

IGF1 is known to initiate a number of different signalling cascades including the PI3K and mitogenactivated protein kinase (MAPK) pathways. Using specific inhibitors, we tried to delineate if these pathways were involved in the effects of oleate on IGF responses. The growth of MCF-10A and MCF-7 cells was severely reduced when PI3K was inhibited, and although the proliferative effect of oleate on MCF-10A cells was blocked, IGF1 was able to induce the proliferation of both MCF-10A (Fig. 4B) and MCF-7 cells (Fig. 4E) independent of $\mathrm{PI} 3 \mathrm{~K}$ in the presence of oleate. Therefore, the differential effect of oleate on the response of these two cell lines was lost when PI3K was inhibited. In the presence of the MEK1 inhibitor, UO126, although basal cell growth was reduced, IGF1 was still able to induce cell proliferation, and oleate was still able to enhance the response of MCF-10A cells (Fig. 4C) and inhibit the response of MCF-7 cells (Fig. 4F). 


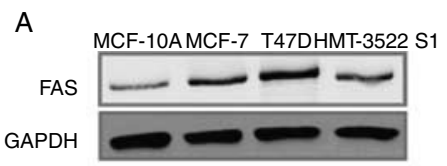

B $\quad$ MCF-7

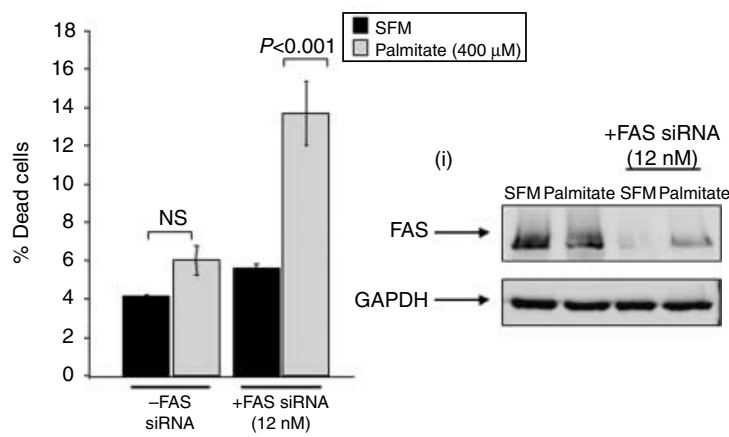

Figure 2 FAS over-expression mediates the resistance to palmitate-induced cell death in malignant MCF-7 breast epithelial cells. (A) MCF-10A, HMT-3522 S1, MCF-7 and T47D cells were seeded in T25 flasks at $0.5 \times 10^{6}$ cells in GM for $24 \mathrm{~h}$ followed by $72 \mathrm{~h}$ in SFM. Western immunoblotting was used to assess FAS abundance. (B) MCF-7 cells were seeded at $0.025 \times 10^{6}$ cells/well in 24 -well plates in GM, $\pm F A S$ and non-silencing siRNA (12 $\mathrm{nM}$ ) before being switched to SFM for $24 \mathrm{~h}$ prior to dosing with palmitate $(400 \mu \mathrm{M})$ for $24 \mathrm{~h}$. The graph represents changes in cell death, and shows the mean \pm S.E.M. of three experiments, each repeated in triplicate. (Bi) A representative western immunoblot of FAS from the experiments described in (B).

\section{Hyperglycaemia reduces the efficacy of chemotherapeutic drugs in malignant breast epithelial cells but not in non-malignant breast epithelial cells: involvement of FAS and ceramide}

The induction of cell death by chemotherapeutic agents is important for the clinical management of breast cancer. As we had shown that breast cancer cells express high levels of FAS, which via the production of endogenous palmitate rendered the cells resistant to death induced by exogenous palmitate; we then examined whether increasing the levels of substrate for this pathway (glucose) affected sensitivity to clinically important inducers of cell death. When the malignant MCF-7 or T47D cells were exposed to hyperglycaemic conditions $(25 \mathrm{mM})$, they became relatively resistant to apoptosis induced by either 5-fluorouracil, doxorubicin or paclitaxel compared with cells grown in euglycaemic conditions $(5 \mathrm{mM}$; Fig. 5C and D). In contrast, levels of glucose had no effect on the sensitivity of non-malignant MCF-10A or HMT-3522 S1 breast epithelial cells to either 5-fluorouracil, doxorubicin or paclitaxel (Fig. 5A and B). Since glucose is a substrate for FAS, which as we confirmed is up-regulated in malignant cells than in non-malignant breast epithelial cells (Fig. 2A) and as FAS appeared to confer survival against death induced by palmitate (Fig. 2B), we investigated if FAS also mediated hyperglycaemia-induced resistance to the chemotherapeutic drugs in the malignant MCF-7 and T47D cells. The resistance of MCF-7 cells to paclitaxel conferred by hyperglycaemic conditions $(P<0.001)$ was completely abrogated when FAS was inhibited by C75 (Fig. 6A). Similarly, in the T47D cells, the resistance to 5-fluorouracil conferred by hyperglycaemic conditions $(P<0.001)$ was also blocked in the presence of C75 (Fig. 6C). These data show that FAS mediated the resistance to chemotherapeutics in a high glucose environment. Since the main product of FAS is palmitate, which is a precursor for de novo ceramide synthesis and the death induced by palmitate was abrogated when ceramide synthesis was inhibited (Fig. 1D), we examined hyperglycaemiainduced resistance to chemotherapy with ceramide production inhibited by fumonisin B1. In the presence of the ceramide synthase inhibitor, the hyperglycaemia-induced resistance to paclitaxelinduced death of the MCF-7 cells $(P<0.001$; Fig. 6B) and that to 5-fluorouracil-induced death of the T47D cells $(P<0.05$; Fig. 6D) were also completely blocked.

\section{Discussion}

Women who develop breast cancer are increasingly also affected by metabolic disorders, and recent clinical studies indicate that these women do worse than women who are in good metabolic control. In addition, glucose acts as a substrate for FAS, the expression of which positively correlates with aggressive tumours and poorer prognoses in various cancers (Kuhajda 2000). FAS is a key enzyme responsible for the de novo synthesis of the fatty acid, palmitate (Kuhajda et al. 1994), which itself is a precursor for ceramide synthesis. Ceramide plays an important role in intracellular signalling, and is known to mediate the apoptotic effects of a number of different chemotherapeutic agents (Claus et al. 2009).

\section{Palmitate induces cell death in malignant cells but not in non-malignant cells}

The saturated fat palmitate has been shown previously to induce apoptosis in many cell types via its metabolism resulting in the production of ceramide (Shimabukuro et al. 1998, Sabin et al. 2007b). We observed that exogenously added palmitate exerted differential effects on cell death in the non-malignant 
B

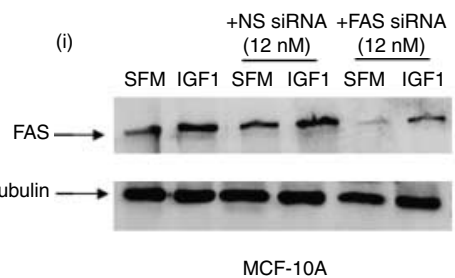

A

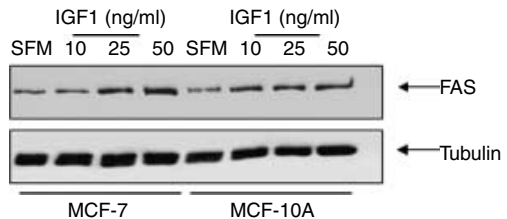

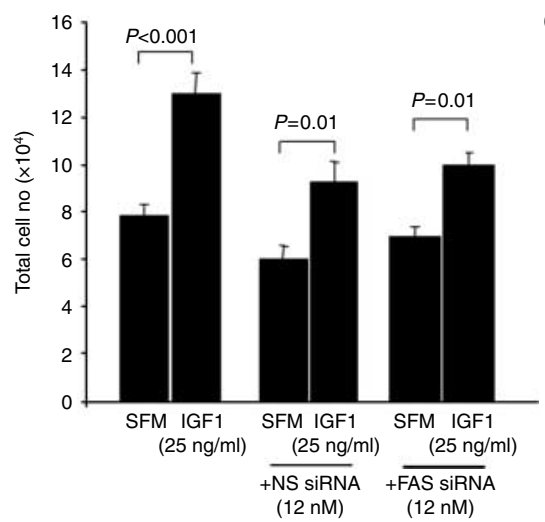

C

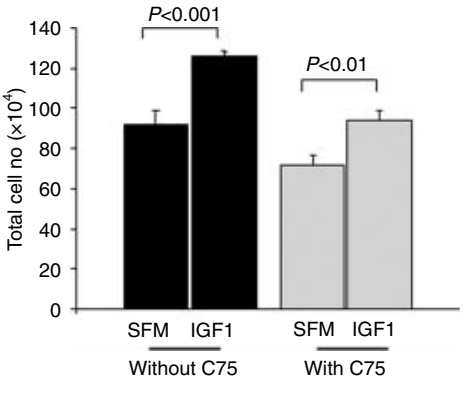

D

+NS SiRNA +FAS siRnA
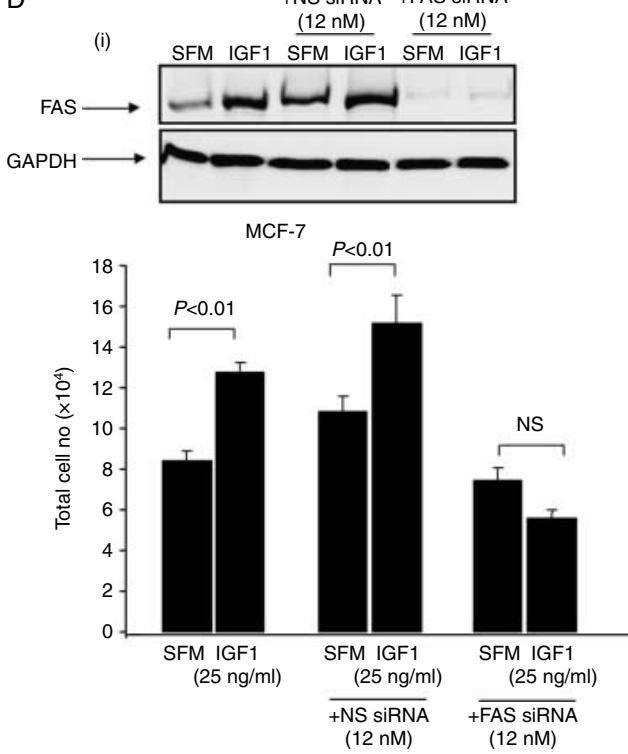

E

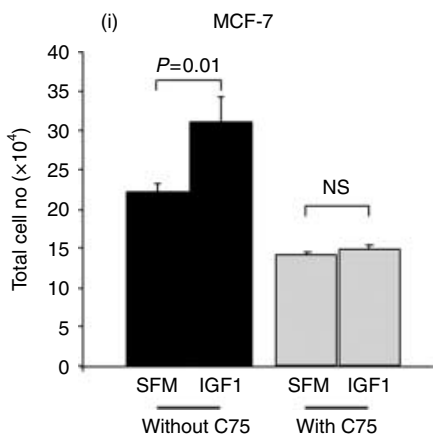

Figure 3 IGF1 regulates abundance of FAS (A). MCF-7 and MCF-10A cells were seeded as described in the legend of Fig. 2A, then dosed with IGF1 (0-50 ng/ml) for $48 \mathrm{~h}$ and processed for FAS abundance by western immunoblotting. (A) A representative blot from experiments repeated three times (B). MCF-10A cells were seeded at $0.05 \times 10^{6}$ cells/well in 24 -well plates in GM $\pm F A S$ and nonsilencing siRNA (12 $\mathrm{nM}$ ) before being switched to SFM for $24 \mathrm{~h}$ prior to dosing with IGF1 ( $25 \mathrm{ng} / \mathrm{ml})$ for $48 \mathrm{~h}$. (Bi) A representative western immunoblot for FAS from the experiments described in (B). (C) MCF-10A cells were seeded as described in the legend of Fig. 1 , and dosed with IGF1 (25 ng/ml) \pm C75 for $48 \mathrm{~h}$. (D) MCF-7 cells were seeded at $0.025 \times 10^{6}$ cells/well in GM in 24 -well plates \pm FAS and non-silencing siRNA (12 nM) before being switched to SFM for $24 \mathrm{~h}$ prior to dosing with IGF1 (25 ng/ml) for $48 \mathrm{~h}$. (Di) A representative western immunoblot for FAS from the experiments described in (D). (E) MCF-7 cells were seeded as described in the legend of Fig. 1, and dosed with IGF1 $(25 \mathrm{ng} / \mathrm{ml}) \pm \mathrm{C} 75$ for $48 \mathrm{~h}$. All graphs represent changes in total cell number, and show the mean \pm S.E.M. of three experiments, each repeated in triplicate.

and malignant cells. Palmitate caused a marked induction of death of the non-malignant cells, whereas the malignant cells were resistant to these effects. Using an inhibitor of ceramide production, we found that the cell death induced by palmitate in the non-malignant cells was mediated via its conversion to ceramide. In contrast, Hardy et al. (2003) observed that oestrogen receptor-negative MDA-MB-231 cells were not resistant to exogenously added palmitate, and underwent apoptosis. 
A

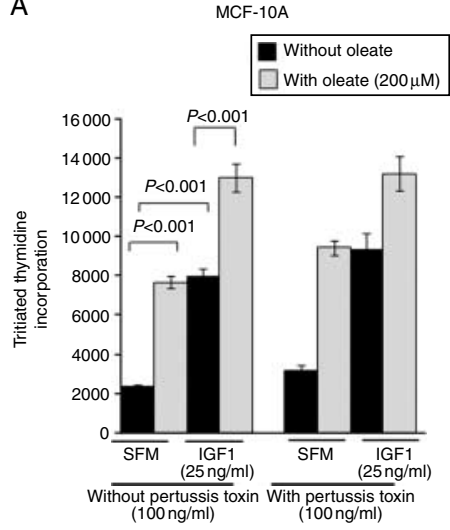

D
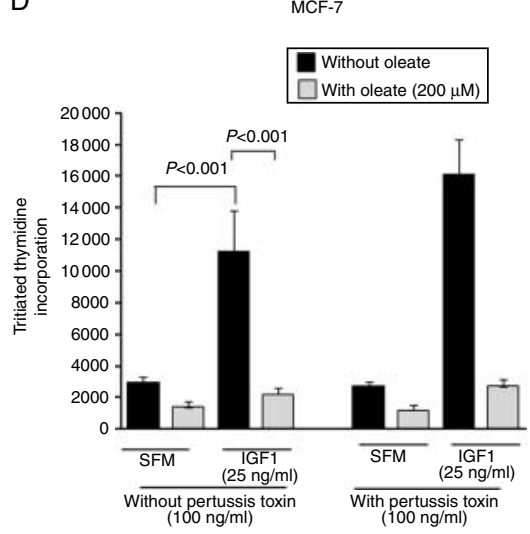

B

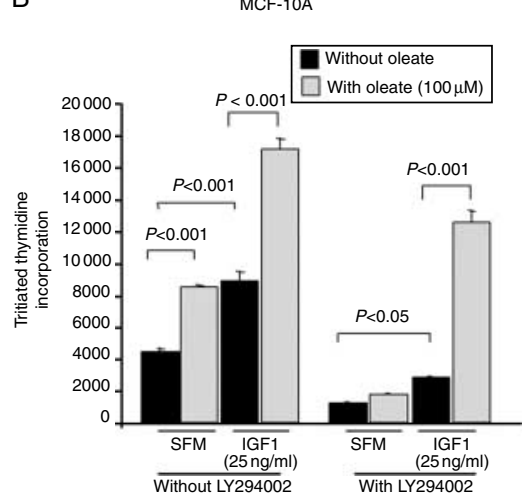

E

C $\quad$ MCF-10A

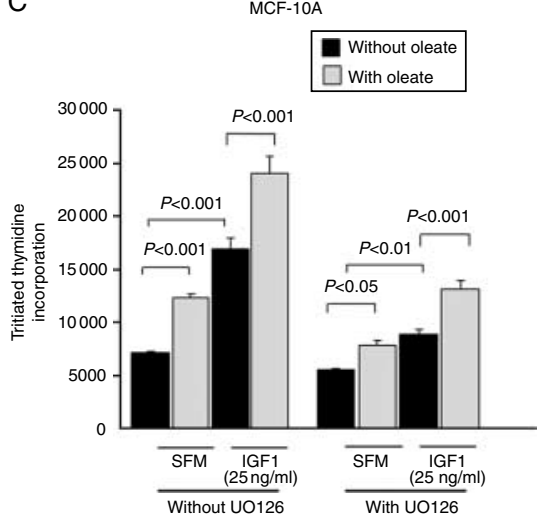

F
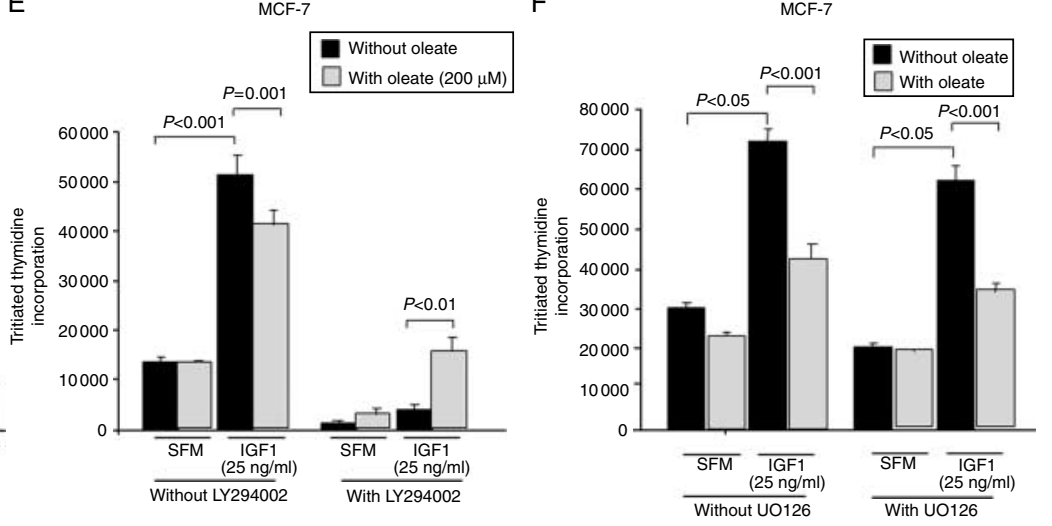

Figure 4 Oleate, but not palmitate, modulates IGF-induced growth. MCF-10A (A-C) and MCF-7 (D-F) cells were seeded at 0.05 $\times 10^{6}$ and $0.025 \times 10^{6}$ cells/well respectively in 24 -well plates in GM before being switched to SFM for a further $24 \mathrm{~h}$. Both cell lines were dosed with IGF1 (25 ng/ml) \pm oleate (100 or $200 \mu \mathrm{M}$ respectively) \pm PT (100 ng/ml; A and D respectively) $\pm \mathrm{LY} 294002(5$ and $7.5 \mu \mathrm{M}$ respectively; $\mathrm{B}$ and $\mathrm{E}) \pm \mathrm{U} 0126$ (1.5 and $1 \mu \mathrm{M}$ respectively; $\mathrm{C}$ and $\mathrm{F}$ ) for $48 \mathrm{~h}$. Graphs represent changes in tritiated thymidine incorporation, and show the mean \pm S.E.M. of three experiments, each repeated in triplicate.

We found that palmitate-induced cell death in the non-malignant cells was protected by oleate. In other cell types, we and others have shown that unsaturated fatty acids such as oleate achieve this by channelling palmitate into triglyceride pools and away from pathways leading to apoptosis (Listenberger et al. 2003, Sabin et al. 2007a). Interestingly, one of the most potent survival factors IGF1 was unable to protect against palmitate-induced cell death of the nonmalignant cells. We showed previously that the presence of sub-apoptotic doses of exogenous ceramide negated the effects of IGF1 on malignant cells (Perks et al. 1999), and suggest that the endogenous ceramide production induced by palmitate may be negating the ability of IGF1 to act as a survival factor.

\section{FAS is over-expressed in malignant cells}

We compared FAS abundance in our cell lines, and confirmed that the malignant cells markedly overexpress FAS relative to the non-malignant cells, as has been described previously (Milgraum et al. 1997). In normal tissue, FAS levels are generally low as the requirement of quiescent cells for fatty acids is generally provided via dietary fatty acids. Overexpression of FAS in cancer cells suggests that tumours require higher levels of fatty acids than can be acquired from the circulation, but also indicates higher levels of endogenous palmitate production.

\section{FAS over-expression mediates the resistance to palmitate-induced cell death in malignant cells}

The resistance of malignant cells to exogenous palmitate-induced death was abolished by blocking or knocking down FAS, suggesting that FAS overexpression had culminated in enhanced endogenous palmitate and a consequent tolerance to exogenously added palmitate. These data imply that palmitate could indirectly favour tumour growth via its ability to specifically induce apoptosis of the non-malignant cells, and thus provide malignant cells with a survival 
advantage. It may also have important implications for the response of cancer cells to many chemotherapeutic agents that have cytotoxic effects mediated via induction of ceramide production (Repicky et al. 2008).
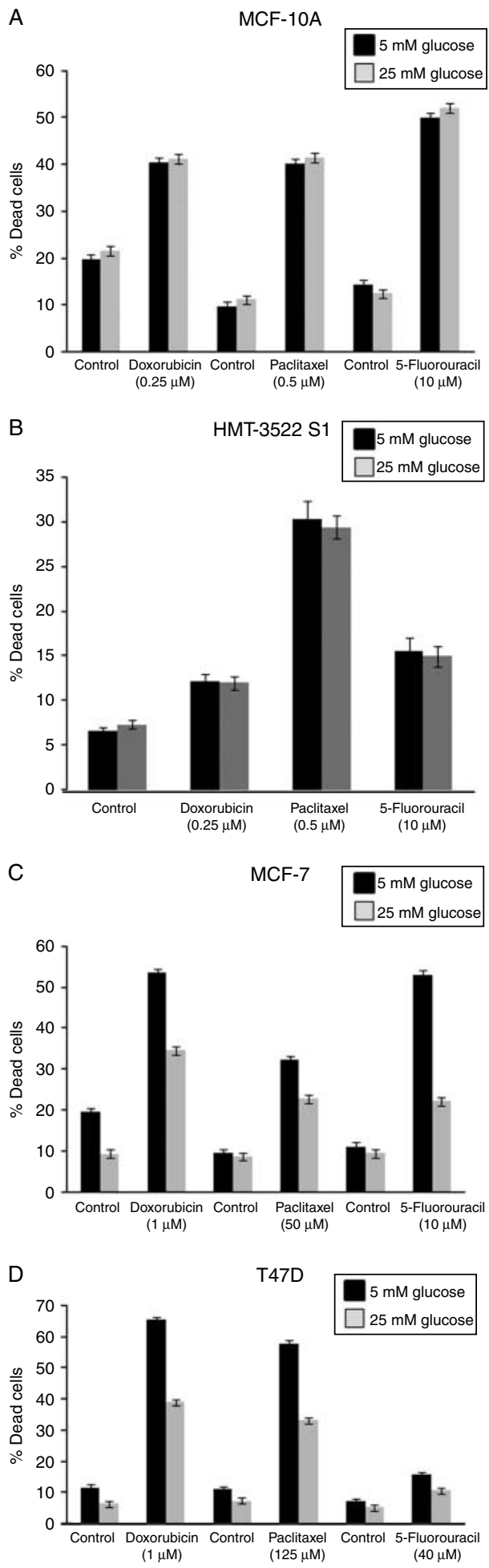

\section{IGF1 regulates FAS abundance}

Despite the extensive literature showing that overexpression of FAS in tumours relates to poorer prognoses (Kuhajda 2000), there is a paucity of data relating to factors that may regulate FAS hyperactivity and over-abundance in tumours. We found that IGF1 increased the abundance of FAS in both non-malignant and malignant cells, but blocking FAS only blocked IGF-induced proliferation in the malignant cells. This suggests that malignant cells have acquired a dependence on FAS for IGF-induced growth. Since there is a clear role for IGF1 in breast cancer and this in part relates to its ability to act as a mitogen, our data suggest that FAS plays an important role in these effects of IGF1 enabling cancer cells to maintain high levels of cell proliferation and survival.

\section{Oleate differentially affects the growth of malignant cells compared with non-malignant cells}

Although palmitate differentially affected the cell death of the non-malignant and malignant cells, we observed that it had no effect on IGF-induced growth. In contrast, the unsaturated fat oleate (the other predominant circulating fatty acid increased in association with obesity) had no effect on cell death, but it did have differential effects on IGF-induced growth of non-malignant and malignant cells. In the nonmalignant cells, oleate promoted growth on its own, and exerted an additive increase in growth when together with IGF1. In contrast, oleate had no effect on the growth of malignant cells alone, but it inhibited IGF-induced proliferation. These findings are consistent with a number of other studies. In vitro studies reported that exposure of breast cancer cells to oleic acid resulted in the down-regulation of Her-2/neu, an oncogene overexpressed in $\sim 20 \%$ of breast carcinomas (Menendez et al. 2005a). In a rat model of dimethylbenz( $\alpha$ )anthracene-induced mammary carcinogenesis, a diet rich in olive oil resulted in a much slower progression of the

Figure 5 Hyperglycaemia reduces the efficacy of chemotherapeutic drugs in malignant breast epithelial cells but not in non-malignant breast epithelial cells. MCF-10A, HMT-3522 S1, MCF-7 and T47D cells were seeded as described in the legend of Fig. 1 in normal (5 mM) glucose-containing GM, and after $24 \mathrm{~h}$, the cells were switched to either high $(25 \mathrm{mM})$ or normal $(5 \mathrm{mM})$ glucose-containing SFM for a further $24 \mathrm{~h}$ prior to dosing with doxorubicin (MCF-10A and HMT-3522 S1 cells: $0.25 \mu \mathrm{M}$, and MCF-7 and T47D cells: $1 \mu \mathrm{M}$ ), paclitaxel (MCF-10A and HMT-3522 cells: $0.5 \mu \mathrm{M}$, and MCF-750 $\mu \mathrm{M}$ and T47D cells: $125 \mu \mathrm{M}$ ) or 5-fluorouracil (MCF-10A, HMT-3522 S1 and MCF-7 cells: $10 \mu \mathrm{M}$, and T47D cells: $40 \mu \mathrm{M}$ ) for a further $24 \mathrm{~h}$. Graphs represent changes in cell death, and show the mean \pm S.E.M. of three experiments, each repeated in triplicate. 
A
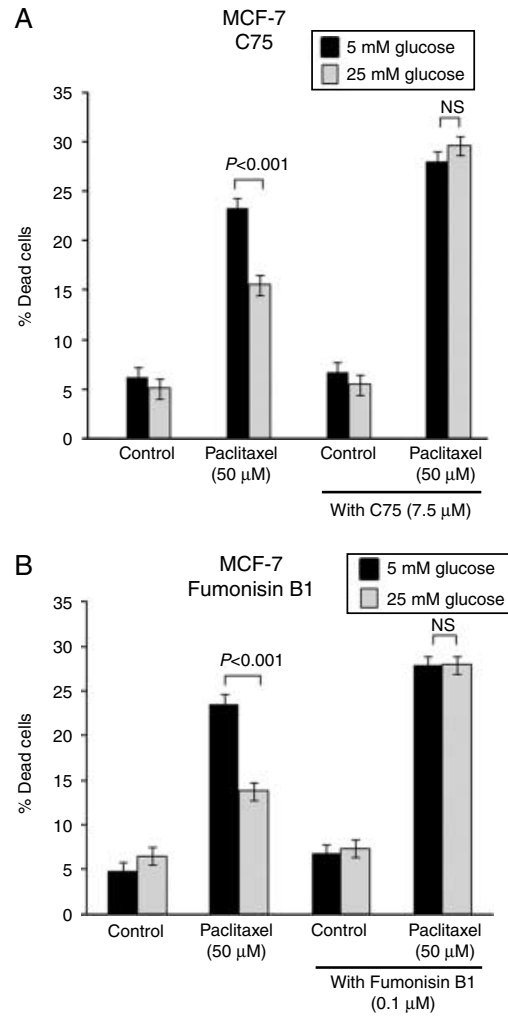

C

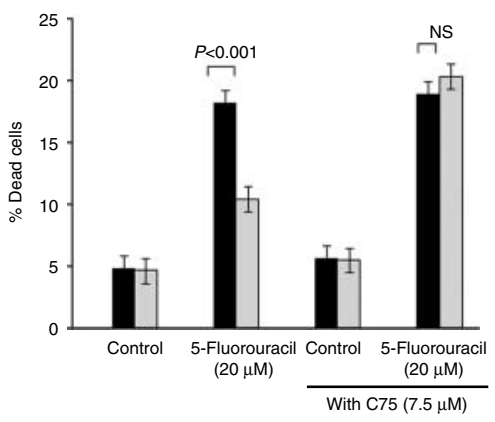

D
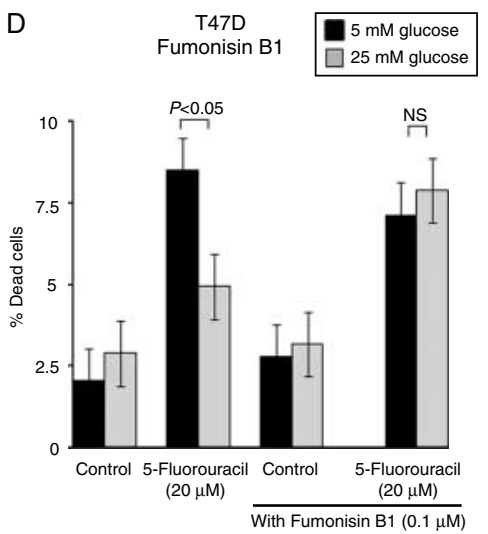

tumours (Solanas et al. 2002, Costa et al. 2004). Epidemiological data have also suggested an effect in women. High mammographic breast density (H-MBD) is associated with greater breast cancer risk, and in the European Prospective Investigation into Cancer and Nutrition study, women who reported olive oil intake $\geq 30.5 \mathrm{~g} /$ day were $30 \%$ less likely to be classified into the H-MBD group (Masala et al. 2006).

We next investigated how oleate was able to differentially modulate IGF-induced proliferation in the non-malignant and malignant cell lines. One report implicated a role for GPCRs in mediating oleate responses in breast cancer cells (Hardy et al. 2005). We found that a GPCR inhibitor, PT, inhibited the ability of a well-characterised agonist of GPCR, S-1P, to induce cell proliferation in both non-malignant and malignant cells. However, PT had no effect on the ability of oleate, at the physiological doses used, to modulate IGF responses in either non-malignant or malignant cells, suggesting that the effects of oleate on IGF-responses were not mediated via GPCR. Although our results may appear to differ from those of Hardy et al. (2005), they also found that MCF-7 breast cancer cells responded poorly to oleate, and it was only when over-expressing GPR40 that they observed a robust proliferative response to oleate (Hardy et al. 2005). A recent paper reported differential effects of oleate on cell proliferation; oleate at $400 \mu \mathrm{M}$ concentration promoted the growth of malignant cells, but not that of non-malignant cells (Soto-Guzman et al. 2008). In contrast, we found that the MCF-7 malignant cells were poorly responsive to oleate as reported previously (Hardy et al. 2005), whereas we observed a significant proliferative effect in the non-malignant cells at $100 \mu \mathrm{M}$ oleate concentration.

IGF1 is known to initiate a number of different signalling cascades including the PI3K and MAPK pathways, which contribute to tumour cell proliferation. In addition, EGFR-induced activation of both MAPK and PI3K signalling cascades has been associated with the over-expression of FAS in prostate cancer cells (Swinnen et al. 2003). We found that in the malignant MCF-7 cells, oleate inhibited IGF-induced growth that was predominantly mediated by PI3K, but when this pathway was blocked, the effect of oleate

Figure 6 Involvement of FAS and ceramide in the protective effects of hyperglycaemia against chemotherapeutic drugs. MCF-7 and T47D cells were seeded as described in the legend of Fig. 5. MCF-7 and T47D cells were dosed with either paclitaxel $(50 \mu \mathrm{M})$ or 5 -fluorouracil $(20 \mu \mathrm{M})$ respectively with or without C75 $(7.5 \mu \mathrm{M})(\mathrm{A}$ and $\mathrm{C})$ or fumonisin $\mathrm{B} 1(0.1 \mu \mathrm{M})(\mathrm{B}$ and $\mathrm{D})$. Graphs represent changes in cell death, and show the mean \pm S.E.M. of three experiments, each repeated in triplicate. 
was switched to enhancing the growth response to IGF1, as in the non-malignant cells, independently of PI3K. Such a modulation of IGF signalling by oleate could have important implications for cancer therapies that are in development targeting IGF and PI3K signalling in obese patients, and warrants further investigation. There have been several reports of crosstalk between IGF1R and ErB/Her receptors, including reports of direct interactions between IGF1R and HER2 in breast cancer cells (Jin \& Esteva 2008), and it has been reported that the suppression of FAS leads to the repression of HER2/neu oncogene expression (Menendez et al. 2004a). Crosstalk between IGF1R and FAS-mediated HER2 activity could be invoked to explain our data showing that MCF-7 cells fail to proliferate in response to IGF1 when FAS is suppressed; however, it has been reported that MCF-7 cells express high levels of IGF1R but not high levels of HER2 (Chakraborty et al. 2008), and whether the effect of FAS suppression on IGF response involves HER2 requires further investigation. It is well established that in obesity the associated increase in fatty acids, particularly saturated fats, affects insulin sensitivity in metabolic tissues. Our data indicate that these fatty acids also affect IGF1 actions on epithelial cells, and that while the unsaturated fat oleate favoured the growth of non-malignant cells, the saturated fat palmitate could differentially provide a survival advantage for malignant epithelial cells.

\section{Hyperglycaemia reduces the efficacy of chemotherapeutic drugs in malignant breast epithelial cells but not in non-malignant breast epithelial cells: involvement of FAS and ceramide}

Several studies have indicated that diabetes is associated with poor prognosis and an increase in cancer mortality, and that it can affect cancer therapy (Richardson \& Pollack 2005, Wolf et al. 2005). The interactions between diabetes and breast cancer are complex, and there is little evidence to indicate why breast cancer therapies should be less effective in patients with concurrent diabetes. We assessed if hyperglycaemic conditions associated with diabetes could affect the sensitivity of malignant breast cancer cells to undergo cell death induced by current drugs including 5-fluorouracil, doxorubicin and paclitaxel. We observed that the level of glucose (normal or high) made no difference to the response of the nonmalignant cells to any of the drugs. In contrast, when the malignant cells were grown in hyperglycaemic conditions, they became resistant to drug-induced cell death compared with when grown in euglycaemic conditions. The sensitivity to chemotherapeutic drugs in hyperglycaemic conditions could however be restored by either inhibiting FAS or the downstream production of ceramide. This suggests that with elevated expression of FAS, the exposure of malignant cells to hyperglycaemia results in increased generation of endogenous palmitate and ceramide, with the cells then acquiring tolerance to cellular stresses whose effects are mediated via intracellular ceramide generation. These data have important therapeutic implications as they indicate that optimising glycaemic control in patients with breast cancer and concurrent diabetes undergoing chemotherapy may improve treatment response rates.

\section{Summary}

Collectively, our data show that FAS mediates IGF-induced growth, the resistance to palmitateinduced cell death and the resistance induced by hyperglycaemia against chemotherapy-induced cell death of malignant breast epithelial cells. Based on the implications of our data, we feel that it would be important to confirm our findings using in vivo models, since understanding the mechanisms involved in the association between obesity, diabetes and metabolic disturbances and breast cancer may lead to more effective use of existing therapies, new therapeutic targets and more tailored treatment of breast cancer patients.

\section{Declaration of interest}

The authors declare that there is no conflict of interest that could be perceived as prejudicing the impartiality of the research reported.

\section{Funding}

This work was supported by the American Institute for Cancer Research (Grant number 05A110).

\section{References}

Abrahamson PE, Gammon MD, Lund MJ, Flagg EW, Porter PL, Stevens J, Swanson CA, Brinton LA, Eley JW \& Coates RJ 2006 General and abdominal obesity and survival among young women with breast cancer. Cancer Epidemiology, Biomarkers and Prevention 15 1871-1877.

Baron JA, Weiderpass E, Newcomb PA, Stampfer M, Titus-Ernstoff L, Egan KM \& Greenberg ER 2001 
Metabolic disorders and breast cancer risk (United

States). Cancer Causes and Control 12 875-880.

Baserga R, Peruzzi F \& Reiss K 2003 The IGF-1 receptor in cancer biology. International Journal of Cancer $\mathbf{1 0 7}$ 873-877.

Burrows C, Holly JM, Laurence NJ, Vernon EG, Carter JV, Clark MA, McIntosh J, McCaig C, Winters ZE \& Perks CM 2006 Insulin-like growth factor binding protein 3 has opposing actions on malignant and nonmalignant breast epithelial cells that are each reversible and dependent upon cholesterol-stabilized integrin receptor complexes. Endocrinology 147 3484-3500.

Calle EE \& Thun MJ 2004 Obesity and cancer. Oncogene 23 6365-6378.

Carroll KK 1977 Dietary factors in hormone-dependent cancers. Current Concepts in Nutrition 6 25-40.

Chakraborty AK, Liang K \& DiGiovanna MP 2008 Co-targeting insulin-like growth factor I receptor and HER2: dramatic effects of HER2 inhibitors on nonoverexpressing breast cancer. Cancer Research $\mathbf{6 8}$ 1538-1545.

Claus RA, Dorer MJ, Bunck AC \& Deigner HP 2009 Inhibition of sphingomyelin hydrolysis: targeting the lipid mediator ceramide as a key regulator of cellular fate. Current Medicinal Chemistry 16 1978-2000.

Coebergh JW, Janssen-Heijnen ML, Post PN \& Razenberg PP 1999 Serious co-morbidity among unselected cancer patients newly diagnosed in the southeastern part of The Netherlands in 1993-1996. Journal of Clinical Epidemiology 52 1131-1136.

Costa I, Moral R, Solanas M \& Escrich E 2004 High-fat corn oil diet promotes the development of high histologic grade rat DMBA-induced mammary adenocarcinomas, while high olive oil diet does not. Breast Cancer Research and Treatment 86 225-235.

Coughlin SS, Calle EE, Teras LR, Petrelli J \& Thun MJ 2004 Diabetes mellitus as a predictor of cancer mortality in a large cohort of US adults. American Journal of Epidemiology 159 1160-1167.

Foti M, Moukil MA, Dudognon P \& Carpentier JL 2004 Insulin and IGF-1 receptor trafficking and signalling. Novartis Foundation Symposium 262 125-141.

Garber K 2004 Energy boost: the Warburg effect returns in a new theory of cancer. Journal of the National Cancer Institute 96 1805-1806.

Hardy S, El-Assaad W, Przybytkowski E, Joly E, Prentki M \& Langelier Y 2003 Saturated fatty acid-induced apoptosis in MDA-MB-231 breast cancer cells. A role for cardiolipin. Journal of Biological Chemistry $\mathbf{2 7 8}$ 31861-31870.

Hardy S, St-Onge GG, Joly E, Langelier Y \& Prentki M 2005 Oleate promotes the proliferation of breast cancer cells via the $\mathrm{G}$ protein-coupled receptor GPR40. Journal of Biological Chemistry 280 13285-13291.

Hems G 1978 The contributions of diet and childbearing to breast-cancer rates. British Journal of Cancer 37 974-982.
Jin Q \& Esteva FJ 2008 Cross-talk between the ErbB/HER family and the type I insulin-like growth factor receptor signaling pathway in breast cancer. Journal of Mammary Gland Biology and Neoplasia 13 485-498.

Key TJ, Verkasalo PK \& Banks E 2001 Epidemiology of breast cancer. Lancet Oncology 2 133-140.

Krone CA \& Ely JT 2005 Controlling hyperglycemia as an adjunct to cancer therapy. Integrated Cancer Therapy 4 25-31.

Kuhajda FP 2000 Fatty-acid synthase and human cancer: new perspectives on its role in tumor biology. Nutrition 16 202-208.

Kuhajda FP, Jenner K, Wood FD, Hennigar RA, Jacobs LB, Dick JD \& Pasternack GR 1994 Fatty acid synthesis: a potential selective target for antineoplastic therapy. PNAS 91 6379-6383.

Landa MC, Frago N \& Tres A 1994 Diet and the risk of breast cancer in Spain. European Journal of Cancer Prevention 3 313-320.

Larsson SC, Mantzoros CS \& Wolk A 2007 Diabetes mellitus and risk of breast cancer: a meta-analysis. International Journal of Cancer 121 856-862.

Listenberger LL, Han X, Lewis SE, Cases S, Farese RV Jr, Ory DS \& Schaffer JE 2003 Triglyceride accumulation protects against fatty acid-induced lipotoxicity. PNAS 100 3077-3082.

Lubin JH, Burns PE, Blot WJ, Ziegler RG, Lees AW \& Fraumeni JF Jr 1981 Dietary factors and breast cancer risk. International Journal of Cancer 28 685-689.

Manco M, Calvani M \& Mingrone G 2004 Effects of dietary fatty acids on insulin sensitivity and secretion. Diabetes, Obesity and Metabolism 6 402-413.

Masala G, Ambrogetti D, Assedi M, Giorgi D, Del Turco MR \& Palli D 2006 Dietary and lifestyle determinants of mammographic breast density. A longitudinal study in a Mediterranean population. International Journal of Cancer 118 1782-1789.

Menendez JA, Lupu R \& Colomer R 2004a Inhibition of tumor-associated fatty acid synthase hyperactivity induces synergistic chemosensitization of HER-2/neu -overexpressing human breast cancer cells to docetaxel (taxotere). Breast Cancer Research and Treatment 84 183-195.

Menendez JA, Vellon L, Mehmi I, Oza BP, Ropero S, Colomer R \& Lupu R $2004 b$ Inhibition of fatty acid synthase (FAS) suppresses HER2/neu (erbB-2) oncogene overexpression in cancer cells. PNAS $\mathbf{1 0 1}$ 10715-10720.

Menendez JA, Lupu R \& Colomer R 2005a Targeting fatty acid synthase: potential for therapeutic intervention in her-2/neu-overexpressing breast cancer. Drug News \& Perspectives 18 375-385.

Menendez JA, Vellon L, Colomer R \& Lupu R $2005 b$

Pharmacological and small interference RNAmediated inhibition of breast cancer-associated fatty acid synthase (oncogenic antigen-519) 
synergistically enhances taxol (paclitaxel)-induced cytotoxicity. International Journal of Cancer 115 19-35.

Michels KB, Solomon CG, Hu FB, Rosner BA, Hankinson SE, Colditz GA \& Manson JE 2003 Type 2 diabetes and subsequent incidence of breast cancer in the Nurses' Health Study. Diabetes Care 26 1752-1758.

Milgraum LZ, Witters LA, Pasternack GR \& Kuhajda FP 1997 Enzymes of the fatty acid synthesis pathway are highly expressed in in situ breast carcinoma. Clinical Cancer Research 3 2115-2120.

Perks CM, Gill ZP, Newcomb PV \& Holly JM 1999 Activation of integrin and ceramide signalling pathways can inhibit the mitogenic effect of insulin-like growth factor I (IGF-I) in human breast cancer cell lines. British Journal of Cancer 79 701-706.

Pollak MN, Schernhammer ES \& Hankinson SE 2004 Insulin-like growth factors and neoplasia. Nature Reviews. Cancer 4 505-518.

Potischman N, Coates RJ, Swanson CA, Carroll RJ, Daling JR, Brogan DR, Gammon MD, Midthune D, Curtin J \& Brinton LA 2002 Increased risk of early-stage breast cancer related to consumption of sweet foods among women less than age 45 in the United States. Cancer Causes and Control 13 937-946.

Rapp K, Schroeder J, Klenk J, Ulmer H, Concin H, Diem G, Oberaigner W \& Weiland SK 2006 Fasting blood glucose and cancer risk in a cohort of more than 140,000 adults in Austria. Diabetologia 49 945-952.

Repicky A, Jantova S \& Milata V 2008 Signal pathways of cell proliferation and death as targets of potential chemotherapeutics. Ceská a Slovenská Farmacie 57 4-10.

Richardson LC \& Pollack LA 2005 Therapy insight: influence of type 2 diabetes on the development, treatment and outcomes of cancer. Nature Clinical Practice. Oncology 2 48-53.

Sabin MA, Crowne EC, Stewart CE, Hunt LP, Turner SJ, Welsh GI, Grohmann MJ, Holly JM \& Shield JP 2007a Depot-specific effects of fatty acids on lipid accumulation in children's adipocytes. Biochemical and Biophysical Research Communications 361 356-361.

Sabin MA, Stewart CE, Crowne EC, Turner SJ, Hunt LP, Welsh GI, Grohmann MJ, Holly JM \& Shield JP $2007 b$ Fatty acid-induced defects in insulin signalling, in myotubes derived from children, are related to ceramide production from palmitate rather than the accumulation of intramyocellular lipid. Journal of Cellular Physiology 211 244-252.

Shafie SM \& Grantham FH 1981 Role of hormones in the growth and regression of human breast cancer cells (MCF-7) transplanted into athymic nude mice. Journal of the National Cancer Institute 67 51-56. Shimabukuro M, Higa M, Zhou YT, Wang MY, Newgard CB \& Unger RH 1998 Lipoapoptosis in beta-cells of obese prediabetic fa/fa rats. Role of serine palmitoyltransferase overexpression. Journal of Biological Chemistry 273 32487-32490.

Silvera SA, Jain M, Howe GR, Miller AB \& Rohan TE 2005 Dietary carbohydrates and breast cancer risk: a prospective study of the roles of overall glycemic index and glycemic load. International Journal of Cancer 114 653-658.

Solanas M, Hurtado A, Costa I, Moral R, Menendez JA, Colomer R \& Escrich E 2002 Effects of a high olive oil diet on the clinical behavior and histopathological features of rat DMBA-induced mammary tumors compared with a high corn oil diet. International Journal of Oncology 21 745-753.

Soto-Guzman A, Robledo T, Lopez-Perez M \& Salazar EP 2008 Oleic acid induces ERK1/2 activation and AP-1 DNA binding activity through a mechanism involving Src kinase and EGFR transactivation in breast cancer cells. Molecular and Cellular Endocrinology 294 81-91.

Soule HD, Maloney TM, Wolman SR, Peterson WD Jr, Brenz R, McGrath CM, Russo J, Pauley RJ, Jones RF \& Brooks SC 1990 Isolation and characterization of a spontaneously immortalized human breast epithelial cell line, MCF-10. Cancer Research 50 6075-6086.

Swinnen JV, Van Veldhoven PP, Timmermans L, De Schrijver E, Brusselmans K, Vanderhoydonc F, Van de Sande T, Heemers H, Heyns W \& Verhoeven G 2003 Fatty acid synthase drives the synthesis of phospholipids partitioning into detergent-resistant membrane microdomains. Biochemical and Biophysical Research Communications 302 898-903.

Talamini R, Franceschi S, Favero A, Negri E, Parazzini F \& La Vecchia C 1997 Selected medical conditions and risk of breast cancer. British Journal of Cancer 75 1699-1703.

Tavani A, Giordano L, Gallus S, Talamini R, Franceschi S, Giacosa A, Montella M \& La Vecchia C 2006 Consumption of sweet foods and breast cancer risk in Italy. Annals of Oncology 17 341-345.

Weiderpass E, Gridley G, Persson I, Nyren O, Ekbom A \& Adami HO 1997 Risk of endometrial and breast cancer in patients with diabetes mellitus. International Journal of Cancer 71 360-363.

Wideroff L, Gridley G, Mellemkjaer L, Chow WH, Linet M, Keehn S, Borch-Johnsen K \& Olsen JH 1997 Cancer incidence in a population-based cohort of patients hospitalized with diabetes mellitus in Denmark. Journal of the National Cancer Institute 89 1360-1365.

Wolf I, Sadetzki S, Catane R, Karasik A \& Kaufman B 2005 Diabetes mellitus and breast cancer. Lancet Oncology 6 103-111.

Yancik R, Wesley MN, Ries LA, Havlik RJ, Edwards BK \& Yates JW 2001 Effect of age and comorbidity in postmenopausal breast cancer patients aged 55 years and older. Journal of the American Medical Association 285 885-892. 